\title{
Mothers' Knowledge, Beliefs, and Practices on Causes and Prevention of Anaemia in Children Aged 6 - 59 Months: A Case Study at Mkuranga District Hospital, Tanzania
}

\author{
Evelyine B. Ngimbudzi'1,2, Alice M. Lukumay', Agnes W. Muriithi' ${ }^{1}$, \\ Khairunnisa A. Dhamani' ${ }^{1}$ Pammla M. Petrucka ${ }^{3,4^{*}}$ \\ ${ }^{1}$ The Aga Khan University, School of Nursing and Midwifery, Dar es Salaam, Tanzania \\ ${ }^{2}$ Mkuranga District Hospital, Mkuranga, Tanzania \\ ${ }^{3}$ College of Nursing, University of Saskatchewan, Regina, Canada \\ ${ }^{4}$ Academics without Borders Volunteer with Aga Khan University, School of Nursing and Midwifery, East Africa \\ Email: " pammla.petrucka@usask.ca
}

Received 24 March 2016; accepted 25 April 2016; published 28 April 2016

Copyright (C) 2016 by authors and Scientific Research Publishing Inc.

This work is licensed under the Creative Commons Attribution International License (CC BY). http://creativecommons.org/licenses/by/4.0/

(c) (i) Open Access

\section{Abstract}

Aims: Anaemia in children aged 6 - 59 months is an important public health problem associated with increasing hospital costs, lengths of hospital stay, and development of complications later in life. Due to the significant caregiver roles of mothers, the level of mothers' knowledge, beliefs and practices are important in addressing anaemia in children. This study investigated knowledge, attitudes, beliefs, and practices of select mothers on anaemia and linked these with known factors for anaemia. Methodology: The case study was conducted at Mkuranga District Hospital, Paediatric Ward between December 2014 and April 2015. A cross-sectional design was used to recruit a convenience sample of $\mathbf{4 0}$ mothers whose children had a confirmed diagnosis of anaemia (through routine laboratory testing). Results: Within the sample, the majority of children were male (52.5\%); aged 6 - 39 months (87.5\%); and had a diagnosis of severe anaemia (75.0\%) according to the World Health Organization's definition. Over one third (35\%) of mothers reported a prior history of anemia in their other children, and the majority (55\%) had heard about anaemia prior to their child's hospitalization. Maternal anaemia was reported by $67.5 \%$ of mothers. Mothers reported that maternal anemia $(17.5 \%)$ and feeding practices $(32.5 \%)$ are known contributing factors to anaemia in children. Mothers reported that anemia could be prevented (55.0\%) and cured by herbal preparations $(\mathbf{4 7 . 5 \% )}$. In addition, some mothers indicated that anaemia was caused by witchcraft $(22.5 \%)$ and eating lemons $(2.5 \%)$. Conclusion: Severe anaemia was high among the studied population which aligned with their hospitalization status. Findings suggested potential

\footnotetext{
*Corresponding author.
} 
gaps in control and management of anemia in children possibly related to low awareness or incorrect knowledge of the relationship between maternal and child anaemia. The findings also highlighted important cultural beliefs related to anaemia. There is an imperative for culturally and socially appropriate knowledge translation and exchange with mothers in order to impact on the prevention and control of anaemia in children in Tanzania.

\section{Keywords}

Anaemia, Children, Tanzania, Maternal Knowledge, Beliefs, and Practices, Culture and Health

\section{Introduction}

Anaemia, as a disease state, is reflected in the reduced presence of red blood cells and concomitantly a lowered hemoglobin concentration; however, its complexity relates to multiple potential pathophysiological causes ranging from genetic to environmental and inconsistent epidemiological surveillance. It is a borderless public health concern which impacts health, socio-economic status, and preferred futures for those most directly impacted. Despite the potential for intervention and treatment, anaemia has remained a major cause of mortality and morbidities regionally and globally [1].

Globally anaemia affects between one-quarter and one-third of the world's population, although some have estimated at risk populations showing $50 \%$ to $80 \%$ incidence primarily due to iron deficiency [2]-[5]. In real numbers, the WHO [6] suggests that approximately 800 million women and children are affected globally. A recent estimate of a $38 \%$ worldwide prevalence of anemia in pregnant women coupled with greater than $50 \%$ of these related to iron deficiency clearly highlights how women and their children are disproportionately affected by anaemia [4]. Anaemia during pregnancy is linked to higher likelihoods of preterm labour, low birth weight, post-natal infection rates, low Apgar scores, and infant/maternal mortality [4] [7]-[9]. The proportion of anaemia is highest in the Africa, with a reported prevalence of $57 \%$ in pregnant women (17 million) and $68 \%$ in preschool children (84 million) [10]. Kassebaum et al. [3] found that anaemia prevalence was highest during the immediate post-natal period followed by ages 1 to 4 , which identifies a potential association between pre and post-natal anaemic states. When looking at children specifically, anaemia is not only life threatening and life shortening, but impacts significantly on quality of life potentials. Commonly reported health problems associated with anaemia in children are impaired growth, reduced cognitive ability, and reduced motor development [11]-[13].

According to the WHO [6] [14], anaemia in children aged 6 to 59 months is defined as haemoglobin (Hb) ranging between: 100 - $109 \mathrm{~g} / \mathrm{L}$ (mild anaemia); 70 - $99 \mathrm{~g} / \mathrm{L}$ (moderate anaemia); and $\leq 70 \mathrm{~g} / \mathrm{L}$ (severe anaemia). Causes of anaemia in children are multifaceted [15] with 50\% of the anemia attributed to iron deficiency [15]. Other causes of anaemia in this subset of children are secondary to underlying risk factors, such as malaria, sickle cell disease, and parasitic infections [16]-[19]. In addition, social determinants of health such as food practices and taboos, cultural beliefs, knowledge, and socioeconomic status contribute to anaemia-related disease burden [19]. The social determinants of health influence the health of populations. Although there is no singular listing of the determinants, there are exemplars from WHO (Europe) and Canada including relevant elements such as "availability of healthy food", "food insecurity”, "unemployment”, "health services”, "gender”, and "race" [20] [21].

The WHO [6] reported 61\% of children aged 6 - 59 months in Tanzania have hemoglobin concentrations of $<110$ g/L [95\% CI: 52, 68] and, of this group, 1.5\% had hemoglobin concentrations of $<70$ g/L [95\% CI: 0.7, 2.8] (p. 24). These findings resulted childhood anaemia being ranked as a severe public health concern in Tanzania (p. 24). The Tanzania Demographic Health Survey indicated that estimated prevalence of moderate to severe anaemia in children aged 6 - 59 months is 6\% [16]. Overall, it is estimated that $72 \%$ of children aged 6 - 59 months are anaemic [22], with anaemia remaining among the top ten causes of hospitalization in children aged under five [16].

This study explored the knowledge, attitudes, beliefs, and practices of select mothers with children aged 6 to 59 months with anaemia as these relate to select social determinants of health, such as unemployment (poverty), 
food insecurity and gender.

\section{Methodology}

\subsection{Study Setting}

The study was conducted at Mkuranga District Hospital between December 2014 and April 2015. As a referral healthcare facility, Mkuranga District Hospital has five wards with an inpatient capacity of 115. Participants were recruited from the 33-bed paediatric ward. The ward receives patients from dispensaries and health centers across the district and, on a case by case basis, from nearby districts. Inpatient stays on the pediatric ward range from 3 to 5 days for anemia diagnosis with the case dispositions for follow-up to the local dispensaries and/or health centers.

\subsection{Study Design and Sampling}

The study was a cross-sectional descriptive design. Convenience sampling was used with the following inclusion criterion:

- Mothers in the paediatric ward with children aged 6 - 59 months having a laboratory confirmed diagnosis of anaemia $(\mathrm{Hb} \leq 100 \mathrm{~g} / \mathrm{L})$,

- Voluntarily agreement to participate in the study,

- Admission date corresponded with data collection dates,

- Ability to speak/read and understand Swahili.

\subsection{Data Collection and Analysis}

Data collection was done in the period from December 2014 to April 2015 using structured closed-ended questionnaires. The instrument was an internally developed tool based on reviewed literature and the researchers' knowledge of the institution and its case complements. The tool development was guided by three main constructs: Knowledge, Beliefs, and Practices. To aid participant understanding, the questionnaires were translated into and delivered in Swahili. Researchers checked the admission book for admitting diagnosis and age of the children. Mothers of children who were screened in (i.e., met the inclusion criteria) were then approached and informed about the study. Once the researchers affirmed mothers' understanding, consent forms and questionnaires were distributed to those willing to participate. For those mothers unable to read and/or write, a researcher assisted them in completing the questionnaire. A total of 40 mothers were surveyed based on the number of willing and available participants during the study period who met the inclusion criteria. The research instrument collected core social and demographic data about the mother/child dyad to augment the chart elements. In addition, the instrument approached the women by asking them for the critical elements related to knowledge, beliefs, and practices, which were subsequently enumerated.

Data entry was done by two researchers. This double independent entry enabled data cleaning and verification in order to identify any missing data and/or incomplete data. Statistical analysis (descriptive level) was done using Microsoft-Excel ${ }^{\mathrm{TM}}$ software.

\subsection{Ethical Consideration}

The study was approved by The Aga Khan University's Ethical Review Sub-committee. Permission to conduct the study at Mkuranga District Hospital was obtained from the District Executive Director's office prior to commencing the study. Participation was voluntary with an informed consent obtained from all participants. Participants who could not read Swahili indicated their willingness to participate by providing their fingerprint after the consent was read to them and any questions were satisfactorily answered.

\section{Results}

\subsection{Characteristics of Study Participants and Households}

A total of 40 mother/child dyads who met the inclusion criteria were recruited into the study and their records were reviewed. The chart review was foundational to revealing the health status (i.e., Hg level; co-morbidities) of the mother and children, which was then augmented by the demographic capture during the survey. Demo- 
graphics showed that 26 (65\%) of the mothers were aged 25 years or more; 28 were married (70\%); 24 (55\%) had primary school education; and 20 (50\%) self-identified as housewives. The majority of the children were male (21 [52.5\%]) aged 6-39 months (31 [77.5\%]). Three-quarters of the children had severe anaemia, while 10 (25\%) had moderate anaemia. In addition to anaemia, 24 (60.0\%) children had additional (secondary) diagnosis. Of these 24 children with co-morbidities were identified with the following breakdown: 54.2\% (13/24) having malaria while 3 had acute respiratory tract infection (12.5\%); 2 had Human Immunodeficiency Virus [HIV] (8.7\%); 2 had sickle cell disease (8.7\%); and 1 each with burn injuries (4.3\%), diarrhoea (4.3\%) and kwashiorkor (4.3\%). Table 1 and Table 2 reveal the demographic characteristics of participating children and mothers.

Table 3 summarizes the characteristics of households and food security profile of study participants. Twentyone (52.5\%) participants were primarily from families with 3 or more children with 14 (35\%) reporting previous childhood anaemia involvement. Although almost two-thirds reported having sufficient money to buy food, although approximately two-fifths (42.5\%) reported household members having slept hungry in the past.

Table 1. Characteristic of mothers participating in the study $(n=40)$.

\begin{tabular}{ccc}
\hline Characteristic & & Number/\% \\
\hline Age (years) & $15-19$ & $4(10.0)$ \\
& $20-24$ & $10(25.0)$ \\
& $25-29$ & $172.5)$ \\
& $30-34$ & $6(15.0)$ \\
Marital status & $35-39$ & $2(2.5)$ \\
& $40-44$ & $28(70.0)$ \\
& Married & $3(7.5)$ \\
Level of education & Divorced & $1(2.5)$ \\
& Widowed & $8(20.0)$ \\
& Not married & $2(5.0)$ \\
Occupation & Form I to IV (secondary) & $22(55.0)$ \\
& Standard I to VII (primary) & $16(40.0)$
\end{tabular}

Table 2. Characteristic of children with anaemia $(n=40)$.

\begin{tabular}{ccc}
\hline Characteristic & & Number of children (\%) \\
\hline Gender & Male & $21(52.5)$ \\
& Female & $19(47.5)$ \\
Age (months) & $6-20$ & $16(40.0)$ \\
& $21-40$ & $15(37.5)$ \\
Anaemia & $41-59(22.5)$ & $10(25.0)$ \\
& Moderate $(70-99 \mathrm{~g} / \mathrm{L})$ & $30(75.0)$ \\
\end{tabular}


Table 3. Characteristics of households of study participants $(n=40)$.

\begin{tabular}{ccc}
\hline \multicolumn{2}{c}{ Characteristic } & Number of households (\%) \\
\hline Number of children & $1-2$ & $19(47.5)$ \\
History of anemia in other children & 3 or more & $14(52.5)$ \\
Number of household members & $<5.0)$ & $14(35.0)$ \\
Family ever slept hungry & 5 or more & $26(65.0)$ \\
Main bread earner & Husband & $28(72.5)$ \\
& Self & $8(20.0)$ \\
Sufficient household funds for food & In-laws & $3(7.5)$ \\
\end{tabular}

\subsection{Mothers' Knowledge, Beliefs, and Attitudes on Childhood Anaemia}

1) Mothers' Knowledge

A slight majority of participants $(n=22 ; 55 \%)$ acknowledged prior knowledge of anaemia, with the majority ( $\mathrm{n}=32 ; 82 \%$ ) reporting the main source of this information as the Reproductive and Child Health (RCH) programs and services. A total of 27 mothers (67.5\%) reported a diagnosis of anaemia during pregnancy and had received treatment ranging from oral medications $(n=25 ; 92.6 \%)$ to blood transfusion $(n=2 ; 7.4 \%)$. The major signs and symptoms of anaemia identified as known by the mothers included a range of early (i.e., conjunctiva and palmar pallor) to late (i.e., difficulty breathing and loss of weight) indicators. Further, the mothers indicated that complications of anaemia were seen in the child becoming less active and unable to learn or retain. The most frequently reported causes of anaemia included frequent illness $(n=12 ; 30.0 \%)$, refusal to eat $(n=10$; $25.0 \%)$, and lack of food at home $(n=9 ; 22.5 \%)$. A small proportion of the participants knew of the connection between maternal anaemia and infant anaemia as well as the link between childhood anaemia and future health conditions. Table 4 provides a comprehensive breakdown of the maternal knowledge of anaemia.

2) Mothers’ Beliefs

Cultural beliefs expressed related to causes of anaemia included witchcraft, local remedies (i.e., herbal preparations), and exclusion of certain foods (i.e., lemons) (see Table 4).

3) Mothers’ Practices

Of note, only $55 \%$ of mothers in this study associated anaemia with feeding practices. Half of the study participants (50\%) reported that they were still breastfeeding their children, although a predictable weaning pattern emerged including maize porridge, ugali (a stiff porridge), and beans. As the primary caregivers, most mothers (72.5\%) reported three feeds per day. Mothers (65.0\%) were the main persons responsible for feeding the child with nearly three-quarters (72.5\%) of children being fed three times a day. Health care accessed for anaemia was most frequently an over the counter medication followed by access to services at a dispensary (primary health care) level. Refer to Table 5 for further consideration of the mothers' practices.

\section{Discussion}

This survey of mothers of children with anaemia admitted at Mkuranga Hospital showed a slightly larger male representation, with $75 \%$ of the children testing as severely anaemic. This latter finding is significantly higher than had been suggested in the reviewed literature, although there continues to be a paucity of relevant epidemiological findings on the prevalence of anaemia. According to national estimates, $27 \%$ of children have mild anaemia, 29\% moderate anaemia, and 2\% severe anaemia [23]. Further, there have been reports of success in reduction of moderate anaemia from 43\% in 2004-05 to 29\% in 2010 [23]. However, in the population studied, 
Table 4. Mothers knowledge and beliefs of anaemia $(n=40)$.

\begin{tabular}{|c|c|c|}
\hline Knowledge base & Specific content & Number of mothers (\%) ${ }^{*}$ \\
\hline \multicolumn{2}{|c|}{ Heard about anaemia before child's admission } & $22(55.0)$ \\
\hline \multicolumn{2}{|c|}{ Diagnosed with anaemia in pregnancy } & $27(67.5)$ \\
\hline \multirow[t]{7}{*}{ Signs \& symptoms of anaemia ${ }^{*}$} & Conjunctiva pallor & $35(87.5)$ \\
\hline & Palmer pallor & $32(80.0)$ \\
\hline & Reduced physical activity & $17(42.2)$ \\
\hline & Loss of appetite & $16(40.0)$ \\
\hline & Loss of weight & $14(35.0)$ \\
\hline & Breathing difficulty & $10(25.0)$ \\
\hline & Puffy face & $8(20.0)$ \\
\hline \multirow[t]{4}{*}{ Complications of anaemia* } & Poor growth & $26(65.0)$ \\
\hline & Tiredness & $20(50.0)$ \\
\hline & Poor learning capacity & $10(25.0)$ \\
\hline & Poor concentration & $6(15.0)$ \\
\hline \multirow[t]{9}{*}{ Causes of anaemia in children ${ }^{*}$} & Frequent illness & $12(30.0)$ \\
\hline & Refusal to eat & $10(25.0)$ \\
\hline & Lack of food at home & $9(22.5)$ \\
\hline & Witchcraft & $9(22.5)$ \\
\hline & Sickle cell & $2(5.0)$ \\
\hline & HIV & $2(5.0)$ \\
\hline & Maternal anaemia & $1(2.5)$ \\
\hline & Eating lemons & $1(2.5)$ \\
\hline & Do not know & $2(5.0)$ \\
\hline \multicolumn{2}{|c|}{ Maternal anaemia relationship to child's anaemia } & $7(17.5)$ \\
\hline \multicolumn{2}{|c|}{ Anaemia causes problems later in life } & $15(37.5)$ \\
\hline
\end{tabular}

${ }^{*}$ Multiple responses were possible.

Table 5. Mothers’ practices related to anaemia.

\begin{tabular}{|ccc}
\hline \multicolumn{1}{c}{ Practices } & & Number of mothers (\%) \\
\hline Still breastfeeding & Maize porridge & $20(50.0)$ \\
& Ugali & $38(95.0)$ \\
& Beans & $27(67.5)$ \\
Foods used during weaning & Cassava porridge & 25(62.5) \\
& Banana stew & $15(37.5)$ \\
& Eggs & $14(35.0)$ \\
\hline
\end{tabular}




\begin{tabular}{|c|c|c|}
\hline Continued & & \\
\hline \multirow{4}{*}{ Number of times child is fed per day } & 2 times & $3(7.5)$ \\
\hline & 3 times & $29(72.5)$ \\
\hline & 4 Times & $4(10.0)$ \\
\hline & On demand & $4(10.0)$ \\
\hline \multirow{4}{*}{ Person responsible for feeding the child } & Mother & $26(65.0)$ \\
\hline & Others & $1(2.5)$ \\
\hline & Self & $7(17.5)$ \\
\hline & Siblings & $6(15.0)$ \\
\hline \multirow{6}{*}{ First drug given to child } & Anti-Malarial & $5(12.5)$ \\
\hline & Home remedies & $5(12.5)$ \\
\hline & Nothing & $9(22.5)$ \\
\hline & Panadol $^{\mathrm{TM}}$ syrup $^{*}$ & 19 (47.5) \\
\hline & Panadol $^{\mathrm{TM}}$ syrup $^{*}$ and Anti-malarial & $1(2.5)$ \\
\hline & Vitamin supplement & $1(2.5)$ \\
\hline \multirow{6}{*}{ First place child taken for treatment } & Dispensary & 19 (47.5) \\
\hline & Pharmacy & $8(20.0)$ \\
\hline & Health Centre & $3(7.5)$ \\
\hline & Home remedies & $5(12.5)$ \\
\hline & Hospital & $5(12.5)$ \\
\hline & Traditional healer & $1(2.5)$ \\
\hline
\end{tabular}

*Panadol is an anti-pyretic and analgesic product.

the majority of presented with severe anaemia with an $\mathrm{Hb}$ of $<70 \mathrm{~g} / \mathrm{L}$, which may, in part, be the contributing factor to the current hospitalization (i.e., the sickest require hospitalization). In addition, a high prevalence of maternal anaemia (70.9\%) has been identified in the coast region of Tanzania and may be associated with observed escalated prevalence of severe anaemia in children in that region [23]. This observation indicates the need for a longitudinal epidemiological consideration of the potential relationship.

Reviewed evidence reported a range of complications or co-morbidities with anaemia which variably aligned with the findings of this study. The mothers reported poor growth and cognitive skills as well as tiredness as symptoms which were supported by the research [12] [24]-[26]. According to Black, Quigg, Hurley, and Pepper [27], anemia contributes to reduced IQ results. Further, there was limited awareness of the mothers that maternal anaemia was related to their children's anaemia, despite evidence that shows treatment of maternal anemia during pregnancy improve neonatal outcomes such as prematurity, low birth weight, and neonatal mortality [28] [29]. Maternal anaemia in pregnancy is associated with anaemia in children [30] especially in the first year of life [31]. In a survey done in Ghana in (2003), 80.6\% of mothers with anemia also had a child with anemia [32]. Maternal anemia is also associated with increased infant mortality [33]. We did not explore with these mothers their previous pregnancy outcomes (i.e., miscarriages; neonatal mortality) due to the already stressful situation with a severely ill child. In our study, less than a fifth of the mothers reported that maternal anaemia contributed to anaemia in their children. Similar findings were reported in a study done in Indonesia where the majority of mothers did not associate maternal anaemia with their children developing anaemia [34]. Also, some mothers recognized that childhood anemia could have life-long implications for their children which are reflected in the work of Christian et al. [35].

The topic of health literacy and knowledge use is a current global opportunity to improve health outcomes. 
According to the WHO [36], health literacy extends beyond education and communication for health and truly embraces strategies which improve the capacities and motivations of individuals to access and use information to improve health outcomes. A third of mothers reported a previous anaemic incident with other children and acknowledged gaining prior knowledge primarily through the RCH programs and services. Maternal knowledge included an understanding of the link between maternal anaemia and childhood anaemia, feeding practices, and future health conditions. Maternal beliefs included the potential to prevent and/or cure anaemia with local herbal preparations. A significant number of mothers believed that anaemia could be the result of witchcraft and eating lemons. These findings clearly flag an opportunity to work with mothers on the causes and treatments for anaemia, and to help them avert the recidivism from one child to the next of anaemia diagnosis.

Children are significantly affected by socio-economic dynamics in the family. Though it is argued that employment is a source of empowerment for mothers, this is only true if the mother has some control of her income [23]. In this study, $70 \%$ of the mothers were dependent on their husbands to provide food for the family. In Tanzania, though some men involve their wives in deciding the family budget, the most recent demographic survey reported that $45 \%$ of the men autonomously decide how the family earnings are spent [23]. This may affect food purchases and focus on healthier foods, again providing direction for future research studies to assess the relationship between purchases and power over resources in predicting anaemia patterns in children. Further, household characteristics impact the health of the family members and influence socio-economic status of the family. Children from large families have increased likelihood of developing nutrition-related health problems [37], such as iron deficiency anaemia. In Tanzania, the average number of household members is five [23]; of note, the majority (65\%) of our participants had larger families ( 5 or $>5$ household members) and $35 \%$ reported prior history of anaemia in their children.

When related to the social determinant of education, there is clear evidence that level of education and knowledge influences health outcomes of children [38]. In our study, $40 \%$ of the mothers were illiterate, $55 \%$ had primary school education, and only $2 \%$ had studied beyond primary education. There is evidence to suggest that children from households where the parents do not have formal education have increased likelihood of developing anaemia [15] [38]. Specifically, one study found that mothers' knowledge of anaemia also influenced child anaemia and other related health practices [34].

Food insecurity, as a social determinant of health, was considered in terms of reported feeding practices, indicators of hunger, and meal frequencies. Feeding practices contribute to anaemia, generally and iron deficiency anaemia, specifically [37]. Although poor feeding practices affects all family members, children under five are most vulnerable [39]. Only 32\% of the mothers in this study knew that their feeding practices contributed to anaemia in their child. In addition, almost all (95\%) of the mothers preferred maize flour porridge, ugali, and other starches as weaning foods, which Peter, Rumisha, Mashoto, and Malebo [40] indicated are rich in carbohydrates and low in absorbable iron with the exception of fortified foods. A study conducted in Uganda reported that majority of anaemic children were mainly fed with traditional porridge made up of cereals [41]. The authors observed that, although people in Mkuranga engage in fishing activities along the coast, the fish is often sold in order to meet other pressing financial commitments instead of being consumed by the household. These practices, which are often evidence in impoverished settings, lead to inadequate consumption of fish and meat which contributes to higher incidence of iron deficiency anaemia [42]. It is likely that children from households where more meals are available each day are less likely to develop anaemia [15]. The WHO [43] recommends children under 2 years old should be fed at least 4 meals per day and provided additional snacks as required. In Tanzania, $57 \%$ of families have 3 meals per day whereas $41 \%$ only manage 2 meals per day [23]. In this study, the majority of the mothers (72.5\%) were able to feed their children only 3 meals per day, with only $10 \%$ reporting feeding their children the recommended 4 meals per day. Some mothers reported difficulties feeding their families with two fifths reporting that the family had slept hungry in the past. This may be indicative of food shortage in the population studied due low social economic status. Similar findings have been reported elsewhere in Tanzania. For instance, food shortage as a determinant of the number of times the family fed was reported in a study done in northern Tanzania where 75\% of children are less than 3 times a day [37]. According to the WHO [43] inappropriate household feeding practices, such as inadequate intakes, pose greater health implications than the food unavailability.

The final determinant considered in this study was culture. Mothers' cultural beliefs are an important determinant of health outcomes in children. For instance, mothers' belief of the causes of anaemia and traditional treatment for anaemia influences health seeking behaviors and feeding practices [44]. In our study, some moth- 
ers attributed anaemia to outside forces (i.e., witchcraft) or foods eaten during pregnancy (i.e., lemons). In studies, mothers believed that eating mangoes, lemons, eggs, or fish would lead to children developing anaemia [32] [44]. In some African settings, eating vegetables is associated with poverty so meals often comprise of culturally accepted foods such as cassava, maize porridge, and ugali. Timely treatment and management of anaemia is also influenced by cultural beliefs. Mkuranga is an area rich in culture and with strong trends towards use of traditional remedies to treat various illnesses before seeking medical attention (Peter et al., 2014). Nearly 50\% of the mothers believed that anaemia can be treated using herbal preparations, although only $12.5 \%$ mothers gave their child home remedies before seeking medical attention and $2.5 \%$ sought the services of a traditional healer before taking their child to a hospital. Though generally there seems to be some acceptance of formal health care at a higher level than in the past it would be important to further study the potential risks and benefits of utilizing both traditional and Western medical practices to address the anaemia challenge.

Limitations of the study

The study involved a small cross-sectional sample; hence, findings are limited in terms of generalizability. The study was conducted in a hospital setting, implying an acute level of the care needs, which may significantly skew the representativeness of severity and intensity of services related to anaemia. It would be desirable to undertake a large replication study, which considers both institutional and community-based anaemia, to correct for this potential limitation. Further, consideration of immediate post-natal anaemic status in the child and mother would be a significant contribution to reducing and/or managing childhood anaemia.

Strengths of the study

Findings from this case study suggest important anaemia-associated factors in the studied population which relate to the social determinants of education, economic status, food insecurity, and culture. It was useful to learn that the mothers sought primary information through the Reproductive and Child Health Centres which is a key learning in strategizing for future anaemia reduction.

\section{Conclusion}

This study considered the knowledge, beliefs, and practices of a select group of mothers whose children were currently hospitalized due to moderate to severe anaemia. The mothers' beliefs regarding anaemia in their children were frequently informed by cultural beliefs such as witchcraft as a cause of the disease. This finding is important in efforts to address anaemia as practitioners will need to consider these deeply rooted perspectives. Regarding practices, the findings suggested that some practices are cultural/historical (i.e., feeding regimens) but others are health system informed (i.e., medication/treatment regimens). This finding provides an opportunity for providers and policy makers to intervene earlier through earlier information sharing and better health care access for anaemia related conditions. Regardless of the reason for interacting with the women (i.e., sick/well; pregnant/post-partum, etc.), there is an imperative for culturally and socially appropriate knowledge translation and exchange with mothers in order to impact on the prevention and control of anaemia in children in Tanzania.

\section{Acknowledgements}

The authors extend special thanks to the mothers for their participation. We would like to thank District Executive Director, District Medical Officer, and Medical Officer in Charge of Mkuranga District Hospital for their cooperation without which the conduct of the study would have been impossible. We extend our gratitude to Medical Officer in Charge of Mkuranga District Hospital for reviewing the paper. We thank the staff of Mkuranga District Hospital Paediatric Ward for their cooperation throughout the study.

\section{References}

[1] Lozano, R., Naghavi, M., Foreman, K., et al. (2012) Global and Regional Mortality from 235 Causes of Death for 20 Age Groups in 1990 and 2010: A Systematic Analysis for the Global Burden of Disease Study 2010. The Lancet, 380, 2095-2128. http://dx.doi.org/10.1016/S0140-6736(12)61728-0

[2] de Benoist, B., McLean, E., Cogswell, M., Egli, I. and Wojdyla, D. (2008) Worldwide Prevalence of Anaemia 19932005. WHO Global Database on Anaemia. World Health Organization, Geneva.

[3] Kassebaum, N.J., Jasrasaria, R., Naghavi, M., Wulf, S.K., Johns, N., Lozano, R., Murray, C.J.L., et al. (2014) Asystematic Analysis of Global Anemia Burden from 1990 to 2010. Blood, 123, 615-624.

http://dx.doi.org/10.1182/blood-2013-06-508325 
[4] Stevens, G.A., Finucane, M.M., De-Regil, L.M., Paciorek, C., Flaxman, S., Branca, F., et al. (2013) Global, Regional and National Trends in Hemoglobin Concentration and Prevalence of Total and Severe Anemia in Children and Pregnant and Non-Pregnant Women for 1995-2011: A Systematic Analysis of Population Representative Data. The Lancet Global Health, 1, e16-e325. http://dx.doi.org/10.1016/S2214-109X(13)70001-9

[5] Peña-Rosas, J.P, De-Regil, L.M., Dowswell, T. and Viteri, F.E. (2011) Daily Oral Iron Supplementation during Pregnancy. Cochrane Library: Cochrane Pregnancy and Childbirth Group.

[6] World Health Organization (2015) Global Prevalence of Anaemia in 2011. WHO Press, Geneva.

[7] Noronha, J.A., Khasawneh, E.A., Seshan, V., Ramasubramaniam, S. and Raman, S. (2012) Anemia in Pregnancy-Consequences and Challenges: A Review of Literature. Journal of South Asian Federation of Obstetrics and Gynaecology, 4, 64-70. http://dx.doi.org/10.5005/jp-journals-10006-1177

[8] Brabin, B.J., Hakimi, M. and Pelletier, D. (2001) An Analysis of Anemia and Pregnancy-Related Maternal Mortality. Journal of Nutrition, 131, 604S-614S, Discussion 614S-615S.

[9] Patra, S., Pasrija, S., Trivedi, S.S. and Puri, M. (2005) Maternal and Perinatal Outcome in Patients with Severe Anemia in Pregnancy. International Journal of Gynecology and Obstetrics, 91, 164-165. http://dx.doi.org/10.1016/j.ijgo.2005.07.008

[10] K4Health (2008) Anemia Prevalence, Causes, and Consequences. USAID: Office of Population and Reproductive Health, Bureau for Global Health. Cooperative Agreement \#AID-OAA-A-13-00068 with the Johns Hopkins University.

[11] Chang, S., Zeng, L., Brouwer, I.D., Kok, F.J. and Yan, H. (2013) Effects of Iron Deficiency Anemia in Pregnancy on Child Mental Development in Rural China. Pediatrics, 131, e755-e763. http://dx.doi.org/10.1542/peds.2011-3513

[12] Lozoff, B., De Andraca, I., Castillo, M., Smith, J.B., Walter, T. and Pino, P. (2003) Behavioral and Developmental Effects of Preventing Iron-Deficiency Anemia in Healthy Full-Term Infants. Pediatrics, 112, 846-854.

[13] Madan, N., Rusia, U., Sikka, M., Sharma, S. and Shankar, N. (2011) Developmental and Neurophysiologic Deficits in Iron Deficiency in Children. The Indian Journal of Pediatrics, 78, 58-64. http://dx.doi.org/10.1007/s12098-010-0192-0

[14] WHO (2011) Haemoglobin Concentrations for the Diagnosis of Anaemia and Assessment of Severity. Vitamin and Mineral Nutrition Information System. World Health Organization, Geneva.

[15] Schellenberg, D., Schellenberg, J.R.M.A., Mushi, A., Savigny, D., de Mgalula, L., Mbuya, C. and Victora, C.G. (2003) The Silent Burden of Anaemia in Tanzanian Children: A Community-Based Study. Bulletin of the World Health Organization, 81, 581-590.

[16] Kahigwa, E., Schellenberg, D., Sanz, S., Aponte, J.J., Wigayi, J., Mshinda, H., Alonso, P. and Menendez, C. (2002) Risk Factors for Presentation to Hospital with Severe Anaemia in Tanzanian Children: A Case-Control Study. Tropical Medicine and International Health, 7, 823-830. http://dx.doi.org/10.1046/j.1365-3156.2002.00938.x

[17] National Bureau of Statistics (2013) Tanzania HIV/AIDS and Malaria Health Indicator Survey (THMIS) 2011-12. National Bureau of Statistics, Dodoma.

[18] Korenromp, E.L., Armstrong-Schellenberg, J.R., Williams, B.G., Nahlen, B.L. and Snow, R.W. (2004) Impact of Malaria Control on Childhood Anaemia in Africa-A Quantitative Review. Tropical Medicine \& International Health, 9, 1050-1065. http://dx.doi.org/10.1111/j.1365-3156.2004.01317.x

[19] Smith J.L. and Brooker, S. (2010) Impact of Hookworm Infection and Deworming on Anaemia in Non-Pregnant Populations: A Systematic Review. Tropical Medicine \& International Health, 15, 776-795. http://dx.doi.org/10.1111/j.1365-3156.2010.02542.x

[20] Braveman, P., Egerter, S. and Williams, D.R. (2011) The Social Determinants of Health: Coming of Age. Annual Review of Public Health, 32, 381-398. http://dx.doi.org/10.1146/annurev-publhealth-031210-101218

[21] Commission on Social Determinants of Health (2008) Closing the Gap in a Generation: Health Equity through Action on the Social Determinants of Health. World Health Organization, Geneva.

[22] Ministry of Health and Social Welfare (2008) The National Road Map Strategic Plan to Accelerate Reduction of Maternal, Newborn and Child Deaths in Tanzania 2008-2015. Ministry of Health and Social Welfare, Dodoma.

[23] National Bureau of Statistics (2011) Tanzania Household Demographic Survey. National Bureau of Statistics, Dodoma.

[24] Haas, J.D. and Brownlie, T. (2001) Iron Deficiency and Reduced Work Capacity: A Critical Review of the Research to Determine a Causal Relationship. The Journal of Nutrition, 131, 676S-690S.

[25] Stoltzfus, R. (2005) Iron-Deficiency Anemia: Reexamining the Nature and Magnitude of the Public Health Problem. The Journal of Nutrition, 131, 697-701. 
[26] Heidkamp, R.A., Ngnie-Teta, I., Ayoya, M.A., Stoltzfus, R.J., Mamadoultaibou, A., Durandisse, E.B. and Pierre, J.M. (2013) Predictors of Anemia among Haitian Children Aged 6 to 59 Months and Women of Childbearing Age and Their Implications for Programming. Food and Nutrition Bulletin, 34, 462-479. http://dx.doi.org/10.1177/156482651303400411

[27] Black, M.M., Quigg, A.M., Hurley, K.M. and Pepper, M.R. (2011) Iron Deficiency and Iron-Deficiency Anemia in the First Two Years of Life: Strategies to Prevent Loss of Developmental Potential. Nutrition Reviews, 69, S64-S70. http://dx.doi.org/10.1111/j.1753-4887.2011.00435.x

[28] Kozuki, N., Lee, A.C. and Katz, J. (2012) Moderate to Severe, but Not Mild, Maternal Anemia Is Associated with Increased Risk of Small-for-Gestational-Age Outcomes. The Journal of Nutrition, 142, 358-362. http://dx.doi.org/10.3945/jn.111.149237

[29] Dibley, M.J., Titaley, C.R., d’Este, C. and Agho, K. (2012) Iron and Folic Acid Supplements in Pregnancy Improve Child Survival in Indonesia. American Journal of Clinical Nutrition, 95, 220-230. http://dx.doi.org/10.3945/ajcn.111.022699

[30] Pasricha, S-R., Black, J., Muthayya, S., Shet, A., Bhat, V., Nagaraj, S., Prashanth, N.S., Sudarshan, H., Biggs, B.-A. and Shet, A.S. (2010) Determinants of Anemia among Young Children in Rural India. Pediatrics, 126, e140-e149. http://dx.doi.org/10.1542/peds.2009-3108

[31] Allen, L.H. (2000) Anemia and Iron Deficiency: Effects on Pregnancy Outcome. American Journal of Clinical Nutrition, 71, 1280S-1284S.

[32] Abu, B., Louw, V., Dannhauser, A., Raubenheimer, J. and Van den Berg, L. (2013) Knowledge Attitudes and Practices (KAP) Regarding Iron Deficiency (ID) among Mothers in an Anemia Endemic Population in Northern region of Ghana. Maternal and Child Nutrition, 3, 42-55.

[33] Marchant, T., Armstrong-Schellenberg, J., Nathan, R., Abdulla, S., Mukasa, O., Mshinda, H. and Lengeler, C. (2004) Anaemia in Pregnancy and Infant Mortality in Tanzania. Tropical Medicine \& International Health, 9, 262-266. http://dx.doi.org/10.1046/j.1365-3156.2003.01178.x

[34] Souganidis, E.S., Sun, K., de Pee, S., Kraemer, K., Rah, J.-H., Moench-Pfanner, R., Sari, M., Bloem, M.W. and Semba, R.D. (2012) Relationship of Maternal Knowledge of Anemia with Maternal and Child Anemia and Health-Related Behaviors Targeted at Anemia among Families in Indonesia. Maternal and Child Health Journal, 16, 1913-1925. http://dx.doi.org/10.1007/s10995-011-0938-y

[35] Christian, P., Khatry, S.K., LeClerq, S.C. and Dali, S.M. (2009) Effects of Prenatal Micronutrient Supplementation on Complications of Labor and Delivery and Puerperal Morbidity in Rural Nepal. International Journal of Gynecology \& Obstetrics, 106, 3-7. http://dx.doi.org/10.1016/j.ijgo.2009.03.040

[36] World Health Organization (2009) Background Note: Regional Preparatory Meeting on Promoting Health Literacy. UN ECOSOC. http://www.who.int/healthpromotion/conferences/7gchp/track2/en/

[37] Nyaruhucha, C.N.M., Msuya, J.M., Mamiro, P.S. and Kerengi, A.J. (2006) Nutritional Status and Feeding Practices of Under-Five Children in Simanjiro District, Tanzania, Tanzanian. Health Research. Bulletin, 8, 162-167. http://dx.doi.org/10.4314/thrb.v8i1.14268

[38] Miller, E.M. (2011) Maternal Health and Knowledge and Infant Health Outcomes in the Ariaal People of Northern Kenya. Social Science and Medicine, 73, 1266-1274. http://dx.doi.org/10.1016/j.socscimed.2011.07.009

[39] Onyemaobi, G.A. and Onimawo, I.A. (2011) Anaemia Prevalence among Under-Five Children in Imo State, Nigeria. Australian Journal of Basic Applied Science, 5, 122-126.

[40] Peter, E.L., Rumisha, S.F., Mashoto, K.O. and Malebo, H.M. (2014) Ethno-Medicinal Knowledge and Plants Traditionally Used to Treat Anemia in Tanzania: A Cross Sectional Survey. Journal of Ethnopharmacology, 154, 767-773. http://dx.doi.org/10.1016/j.jep.2014.05.002

[41] Kikafunda, J.K., Lukwago, F.B. and Turyashemererwa, F. (2009) Anaemia and Associated Factors among Under-Fives and Their Mothers in Bushenyi District, Western Uganda. Public Health Nutrition, 12, 2302-2308. http://dx.doi.org/10.1017/S1368980009005333

[42] Bhargava, A., Bouis, H.E. and Scrimshaw, N.S. (2001) Dietary Intakes and Socioeconomic Factors Are Associated with the Hemoglobin Concentration of Bangladeshi Women. The Journal of Nutrition, 131, 758-764.

[43] WHO (2015) Infant and Young Child Feeding Fact Sheet. WHO Press, Geneva.

[44] Agboada, J. (1999) Mothers’ Knowledge, Attitudes, Beliefs and Practices Related to Childhood Anaemia in the Kintampo District. Doctoral Dissertation, University of Ghana, Accra. 